This is the peer reviewed version of the following article: Mölzer, C, Shankar, SP, Griffith, M, Islam, MM, Forrester, JV, Kuffová, L. Activation of dendritic cells by crosslinked collagen hydrogels (artificial corneas) varies with their composition. J Tissue Eng Regen Med.2019, which has been published in final form at https://doi.org/10.1002/term.2903. This article may be used for non-commercial purposes in accordance with Wiley Terms and Conditions for Use of Self-Archived Versions.

\title{
ACTIVATION OF DENDRITIC CELLS BY CROSSLINKED COLLAGEN HYDROGELS (ARTIFICIAL CORNEAS) VARIES WITH THEIR COMPOSITION
}

\section{Running Headline: DC-ACTIVATION VARIES WITH HYDROGEL COMPOSITION}

Christine Mölzer ${ }^{1, \#}$, Sucharita P. Shankar ${ }^{1,+, \#}$, May Griffith ${ }^{2,3}$, M. Mirazul Islam², ${ }^{2}$, John V. Forrester $^{1}$, and Lucia Kuffová ${ }^{1, *}$

${ }^{I}$ School of Medicine and Dentistry, Section of Immunology, Inflammation and Infection, Institute of Medical Sciences, Division of Applied Medicine, University of Aberdeen, Foresterhill, Aberdeen, AB25 2ZD, Scotland, UK.

${ }^{2}$ Dept. of Clinical and Experimental Medicine, Cell Biology Bldg. Level 10, Linköping University, S58185 Linköping, Sweden.

${ }^{3}$ Department of Ophthalmology, University of Montreal and Maisonneuve-Rosemont Hospital Research Centre, 5415 Boulevard de L'Assomption, Montreal, QC, H1T 2M4, Canada.

${ }^{4}$ Schepens Eye Research Institute and Massachusetts Eye and Ear, Department of Ophthalmology, Harvard Medical School, Boston, Massachusetts, USA.

${ }^{+}$Current affiliation: Translational Biomarkers and Bioanalysis, Development Sciences, UCB Pharma, Slough, UK.

${ }^{\#}$ Authors (in alphabetical order) contributed equally to this work.

*Corresponding author:

Dr. Lucia Kuffová

Email:1.kuffova@abdn.ac.uk

$\mathrm{Ph}:+44(0) 1224437523$

Fax: +44 (0)1224 437506 
School of Medicine and Dentistry, Section of Immunology, Inflammation and Infection, Institute of Medical Sciences, Division of Applied Medicine, University of Aberdeen, Foresterhill, Aberdeen, AB25 2ZD, Scotland, UK 


\begin{abstract}
Activated $\mathrm{T}$ cells are known to promote fibrosis, a major complication limiting the range of polymeric hydrogels as artificial corneal implants. As T cells are activated by dendritic cells (DC), minimally activating hydrogels would be optimal. In this study, we evaluated the ability of a series of engineered (manufactured/fabricated) and natural collagen matrices to either activate DC or conversely induce DC apoptosis in vitro. Bone marrow DC were cultured on a series of singly and doubly crosslinked hydrogels (made from recombinant human collagen, RHCIII; or collagen mimetic peptide, $\mathrm{CMP}$ ); or on natural collagen-containing matrices, Matrigel ${ }^{\mathrm{TM}}$ and de-cellularised mouse corneal stroma. Dendritic cell surface expression of MHC Class II and CD86 as well as apoptosis markers were examined. Natural matrices induced low levels of DC activation and maintained a "tolerogenic" phenotype. The same applied to singly crosslinked CMP-PEG gels. RHCIII gels singly crosslinked using either N-(3-dimethylaminopropyl)-N'-ethylcarbodiimide with the co-initiator N-hydroxy succinimide (EDC-NHS) or N-cyclohexyl-N-(2-morpholinoethyl) carbodiimide metho- $p$ toulenesulfonate with NHS (CMC-NHS), induced varying levels of DC activation. In contrast, however, RHCIII hydrogels incorporating an additional polymeric network of 2-methacryloyloxyethyl phosphorylcholine (MPC) did not activate DC but instead induced DC apoptosis, a phenomenon observed in natural matrices. This correlated with increased DC expression of LAIR-1 (leukocyteassociated immunoglobulin-like receptor-1). Despite low immunogenic potential, viable tolerogenic DC migrated into and through both natural and manufactured RHCIII gels. These data show the immunogenic potential of RHCIII gels varies with the nature and composition of the gel. Pre-clinical evaluation of hydrogel immunogenic/fibrogenic potential is recommended.
\end{abstract}

Keywords: dendritic cells, extracellular matrix, collagen hydrogels, activation crosslinkers, transplantation, graft 


\section{INTRODUCTION}

Corneal transplantation is currently the only commonly accepted therapeutic option available for corneal blindness, a worldwide unmet medical need (Shankar, Griffith, Forrester, \& Kuffová, 2015). To address the limited supply of donor human allograft corneas, strategies involving bio-interactive, extracellular matrix (ECM)-based artificial corneal substitutes have been proposed (Griffith et al., 2012). Promising approaches include transplanting host corneal tissue with cell-free recombinant human collagen III (RHCIII)-based hydrogels that mimic natural corneas in composition and optical properties, and have demonstrated functionality in lamellar implants (i.e. intrastromal non-penetrating implants) in both animal models (mini-pigs and rabbits) (Griffith et al., 2012; W. Liu et al., 2008; McLaughlin et al., 2010) and in patients (Per Fagerholm et al., 2010; P. Fagerholm et al., 2014). All collagen hydrogels in these studies were singly crosslinked using N-(3-dimethylaminopropyl)-N'ethylcarbodiimide (EDC) with N-hydroxysuccinimide (NHS) as co-initiator. Mechanical properties including tensile strength, elongation at break, elastic modulus, and toughness of those exact RHCIII gels used in the present study, were investigated earlier focusing on in vivo myeloid responses (Ahn et al., 2013). In addition, a four-year clinical study demonstrated improved visual acuity in patients with no signs of rejection and absence of dendritic cells (DC) in lamellar implants composed of singly crosslinked RHCIII hydrogels (P. Fagerholm et al., 2014).

In terms of reactivity, however, there is a fundamental difference in the host inflammatory/immune response to intrastromal lamellar hydrogel implants and hydrogels which substitute for all five layers of the cornea (i.e. full thickness hydrogel implants). In particular, lamellar implants allow preservation of the host endothelium (the dominant reservoir of immunogenicity in grafted corneas). In contrast, full thickness implants, where the integrity of host endothelium is compromised, depend upon minimising the wound healing response and development of opaque scar tissue (retro-corneal membrane $(\mathrm{RCM})$ formation) to retain transparency. Accordingly, lamellar implants have enjoyed some degree of success (P. Fagerholm et al., 2014; Islam et al., 2018; Jangamreddy et al., 2018) while full thickness implants do not remain clear due to RCM formation in many cases (Hicks \& Hamilton, 2005; Obata \& Tsuru, 2007; Rajendran, Netuková, Griffith, Forrester, 
\& Kuffová, 2017; Yum, Kim, \& Kim, 2013). However, they can function as tectonic grafts allowing preservation of the eye in the case of a non-healing wound and later replacement with a full thickness, endothelium-intact, penetrating allograft. Doubly crosslinked hydrogels, using EDC-NHS crosslinked RHCIII gels combined with the synthetic phospholipid polymer, 2-methacryloyloxyethyl phosphorylcholine (MPC) crosslinked with poly ethylene glycol diacrylate (PEGDA) were stably accepted as tectonic grafts (Buznyk et al., 2015) as well as showing value as anterior lamellar grafts (Islam et al., 2018). In a different report (McLaughlin et al., 2010), however, doubly crosslinked hydrogels comprising porcine type I collagen with MPC, when grafted into the corneas of guinea pigs as full thickness grafts, remained optically clear with no RCM formation. It remains to be clarified, however, whether the additional MPC had a role.

Although RHCIII hydrogels are usually regarded as non-reactive, and able to successfully promote regeneration, like native collagen, they are large biopolymers and relatively difficult to purify or customise. Therefore, short peptide mimics of collagen, known as collagen mimetic peptides (CMP) or collagen-like peptides (CLP) have been developed (O'Leary, Fallas, Bakota, Kang, \& Hartgerink, 2011; Rubert Pérez et al., 2015). In that respect, a 36 amino-acid long CMP chain (O'Leary et al., 2011) was modified by addition of a two amino acid linker (Islam et al., 2016), covalently conjugated to a backbone of mechanically tougher polyethylene glycol (PEG), and subsequently crosslinked (Rubert Pérez et al., 2015). The resulting CMP-PEG stabilised hydrogels were as effective as full-length collagen gels in promoting corneal functional repair as recently shown in mini-pigs (Jangamreddy et al., 2018).

Overcoming immunological challenges is critical for the success of strategies for restoring corneal function in corneal allograft (Anderson, Rodriguez, \& Chang, 2008; Babensee, 2008; Badylak \& Gilbert, 2008; Sefton, Babensee, \& Woodhouse, 2008; Tang \& Eaton, 1995) and similar challenges may influence success of full thickness implants. Professional antigen presenting cells such as DC are key players in determining the outcome of allograft acceptance (Banchereau \& Steinman, 1998; Steinman, 2012). Immunogenic materials activate DC, thereby converting "immature" (naïve) DC (iDC) into "mature" $\mathrm{DC}(\mathrm{mDC})$ with elevated expression of maturation markers such as major 
histocompatibility complex II (MHCII) and co-stimulatory molecules (CD80, CD86) (Babensee, 2008; Badylak \& Gilbert, 2008; Sefton et al., 2008). In contrast, tolerogenic materials neither activate DC nor initiate an adverse immune response (Janeway \& Medzhitov, 2002; van Kooten et al., 2011). The chemical and physical properties of biomaterials, including hydrophobicity (Shankar, Petrie, García, \& Babensee, 2010), control processes such as protein adsorption and complement activation which, as extracellular "danger signals" (PAMPs, DAMPs) bind and activate PRR ligands presented on the DC surface (Reddy, Swartz, \& Hubbell, 2006), determine their immunogenicity. Surgically-induced trauma itself may also drive adverse DC-biomaterial interactions (Jones, 2008) resulting in varying extents of DC maturation with immunogenic potential (Park \& Babensee, 2012). These phenomena have direct implications for the use of artificial corneal hydrogels, particularly full thickness hydrogel implants.

DC present corneal antigens to T cells in the eye-draining lymph node (Dang, Kuffová, Liu, \& Forrester, 2014; Kuffová et al., 2008) and initiate an allo-specific T cell immune response. T cells are also implicated in fibrogenic responses (Farini et al., 2007) which, in the case of rejected corneal grafts and failed prostheses, result in formation of dense fibrous membranes on the posterior corneal surface (retro-corneal membrane, RCM). It is important to determine whether artificial corneal hydrogels may similarly activate DC and promote fibrosis with RCM formation and an increased risk of inflammation.

The objective of this study was, therefore, to assess the potential risk of differentially crosslinked, RHCIII and CMP-PEG hydrogels (Ahn et al., 2013; Rajendran et al., 2017), and their individual components to activate DC using in vitro co-culture assays. We also compared the effects of natural versus engineered collagen-containing matrices on DC and discuss the implications for fabrication of collagen-based hydrogels as corneal implants.

\section{MATERIALS AND METHODS}

\subsection{Culture of bone marrow dendritic cells (BMDC) on hydrogels}

Primary BMDC were cultured as described previously (Inaba et al., 1992) and adapted in (Martin-Granados et al., 2015). Briefly, hindlimb bones of naïve 5-8 weeks old C57BL/6 mice (bred 
and maintained in the Medical Research Facility, University of Aberdeen, Scotland, UK) were flushed to obtain bone marrow and cells depleted of differentiated cells: T cells [CD4 (GK 1.5), CD8a (536.7)], B cells [CD45R/B220 (IHC)] (all antibodies from BD Biosciences, Franklin Lakes, NJ) and $\mathrm{MHCII}^{+}$cells (P7/7; Serotec), by magnetic bead isolation (Dynal Biotech; Dynabeads sheep anti-rat IgG). After seeding (day 0) cells were cultured for another 6 days in the presence of $10 \mathrm{ng} / \mathrm{mL}$ granulocyte-macrophage colony-stimulating factor (GM-CSF; R\&D Systems) in $10 \mathrm{~cm}$ Petri dishes (Falcon) in DC medium [RPMI 1640 (Gibco Glutamax) with $5 \%$ low IgG foetal calf serum (FCS; Gibco) supplemented with $0.2 \mathrm{mM}$ sodium pyruvate (Gibco), $0.1 \mathrm{mM}$ non-essential amino acids (NEAA; Gibco) and 10-5 M 2-mercaptoethanol (2-ME; Gibco), $20 \mathrm{U} / \mathrm{mL}$ of penicillin, $20 \mu \mathrm{g} / \mathrm{mL}$ of streptomycin (both Gibco)]. Medium was replenished on days 2 and 4 of culture. On day 6 of culture loosely adherent and adherent fractions were collected following Accutase treatment (Sigma) (2 $\mathrm{mL} /$ dish, $15 \mathrm{~min}, 37^{\circ} \mathrm{C}$ ). Cells were pooled, depleted of Gr-1 ${ }^{+}$granulocytes (RB6-8C5) and the resulting population of $\mathrm{CD} 11 \mathrm{c}^{+} \mathrm{DC}(\sim 70 \%)$ were used to test $\mathrm{DC}$ activation. All animal experiments complied with the ARRIVE guidelines and were carried out in accordance with the UK Animals (Scientific Procedures) Act, 1986 and associated guidelines.

\subsection{Preparation of natural extracellular matrix}

Naturally occurring extracellular matrix (ECM) scaffolds used in this study included Matrigel $^{\mathrm{TM}}$ (Life Technologies, Paisley, UK) and corneal stromal matrix. Matrigel ${ }^{\mathrm{TM}}$ is an endotoxintested, gelatinous, basement membrane mimetic comprising primarily collagen IV, laminin, entactin and heparin sulphate proteoglycans from murine tumour stroma (CorningInc., 2018). It was reconstituted in situ as soft-gels in flat-bottom 96 -well plates (using $80 \mu \mathrm{L}$ of liquid gel preparation to give a $150-200 \mu \mathrm{m}$ thick soft gel) by incubation at $37^{\circ} \mathrm{C}, 30 \mathrm{~min}$ in $5 \% \mathrm{CO}_{2}$ according to manufacturer instructions, prior to DC culture. Corneal stromal matrix was prepared from normal murine corneas excised from naïve C57BL/6 mice and de-cellularised as published earlier (Zhang et al., 2015). Briefly, corneas were de-cellularised by allowing them to swell in ultrapure water (Baxter; overnight, $4{ }^{\circ} \mathrm{C}$ ), washing alternately with $2 \mathrm{M} \mathrm{NaCl}$ or sterile water with shaking three times each $\left(30 \mathrm{~min}, 4^{\circ} \mathrm{C}\right)$ and placed in sterile-filtered $0.2 \%$ Triton X-100 (Sigma; 6 hours, $4{ }^{\circ} \mathrm{C}$ ). Prior to DC culture, $75 \mu \mathrm{m}$ thick 
corneal stromal matrices were sterilised with $3 \%(\mathrm{v} / \mathrm{v})$ penicillin-streptomycin (Thermo Scientific) and fungizone (Thermo Scientific) overnight at $4{ }^{\circ} \mathrm{C}$ and washed three times with sterile PBS. They were then incubated for 48 hours in cell culture media containing said sterilising agents at $37{ }^{\circ} \mathrm{C}, 5 \% \mathrm{CO}_{2}$ until use (W. Liu et al., 2008), and positioned in flat-bottom 96-well plates. For 'natural' decellularisation of corneas prior to DC culture, egress of resident $\mathrm{CD} 11 \mathrm{c}^{+} \mathrm{DCs}$ was promoted by placing freshly excised corneal buttons (with their epithelium mechanically abraded) in 6-well plates in media (2 ml RPMI with low Ig FCS, $10 \mathrm{mM}$ HEPES, NEAA, penicillin-streptomycin, 2-ME) at $37{ }^{\circ} \mathrm{C}, 5 \%$ $\mathrm{CO}_{2}$ for 6 days with media replenished on days 2 and 4 of culture as described previously (Hamrah, Liu, Zhang, \& Dana, 2003).

\subsection{Preparation of collagen and collagen mimetic matrices}

Sheets of RHCIII (10 \% and $18 \%$ w/w (FibroGen Inc., San Francisco, CA) were crosslinked with two different water soluble carbodiimides: N-(3-dimethylaminopropyl)-N'-ethylcarbodiimide or N-cyclohexyl-N-(2-morpholinoethyl) carbodiimide metho- $p$-toulenesulfonate with NHS (CMC-NHS) (Sigma-Aldrich, St. Louis, MO), and with co-initiator N-hydroxy succinimide (EDC-NHS) (SigmaAldrich, St. Louis, MO) to generate two singly crosslinked gels, namely EDC-NHS and CMC-NHS gels (Table 1). Details for preparation of these hydrogels are given in (Ahn et al., 2013). Briefly, RHCIII was buffered in a syringe mixing system, and $\mathrm{pH}$ adjusted to 5 as needed. Then a calculated amount of crosslinker was added and mixed in. The molar ratio of EDC to crosslinker:collagen-NH2 (collagen$\mathrm{NH} 2$ denotes the e- amine groups on collagen molecules) used was 0.4 while that for CMC to achieve similar physical hydrogel properties was 1.0 . The crosslinking reaction was allowed to proceed at either $0{ }^{\circ} \mathrm{C}$ (ice/water bath) for $\mathrm{EDC} / \mathrm{NHS}$ or $25^{\circ} \mathrm{C}$ (water bath) for $\mathrm{CMC} / \mathrm{NHS}$.

In addition, to enhance their mechanical properties, some EDC-NHS crosslinked gels incorporated a second collagenase-resistant network of 2-methacryloyloxyethyl phosphorylcholine (MPC) (Paramount Fine Chemicals Co. Ltd Dalian, China) (hereafter named MPC gels; doubly crosslinked) crosslinked with PEGDA as described elsewhere (Hayes et al., 2015). Singly crosslinked CMP-PEG hydrogels $(100 \mu \mathrm{m}$ thick) were prepared by conjugation of a $12 \%(\mathrm{w} / \mathrm{w})$ solution of CMP 
(UAB Vildoma, Vilnius, Lithuania) containing a 38 amino acid chain (Cys-Gly-(Pro-Lys-Gly-)4(ProHyp-Gly) ${ }_{4}(\text { Asp-Hyp-Gly) })_{4}$ ) to a $400 \mathrm{kD}$ 8-arm polyethylene glycol-maleimide (PEG, Creative PEGWorks, Durham, NC, USA) using methods described elsewhere (Islam et al., 2016). The resulting CMP-PEG formed a hydrogel after single crosslinking with EDC-NHS (hereafter named CMP-PEG crosslinked hydrogel). The molar equivalent of CMP-PEG-NH2:EDC was 1:2, and that of EDC: NHS was 1:1. All reagents were thoroughly mixed prior to moulding the hydrogel into flat sheets and leaving them in a humidified chamber overnight for crosslinking. All hydrogels were stored in $1 \%$ chloroform saturated phosphate buffered saline (PBS; Oxoid Ltd) at $4{ }^{\circ} \mathrm{C}$ to maintain sterility. The thickness of all of the above mentioned biomaterials amounted to $70-150 \mu \mathrm{m}$.

Finally, individual constituents of RHCIII hydrogels as well as endotoxin-tested, purified bovine collagen I (Trevigen, Gaithersburg, MD) and bovine collagen III (Southern Biotech, Birmingham, AL) were buffered in media and allowed to form soft gels in flat-bottom 96-well plates $\left(37{ }^{\circ} \mathrm{C}, 30\right.$ mins, $\left.5 \% \mathrm{CO}_{2}\right)$. Individual components of CMP-PEG hydrogels including unconjugated PEG 3,350 monodisperse (50 \% w/v; Hampton Research, Aliso Viejo, CA) in ultrapure water (sterile, endotoxin-tested) or non-crosslinked peptides alone on PEG backbones (CMP-PEG uncrosslinked) resuspended in ultrapure water $(<2 \% \mathrm{w} / \mathrm{v})$ and sterile-filtered were also tested. Table 1 and Supplementary Figure S4 provide an overview of those natural and fabricated matrices used in this study.

Table 1 here.

\subsection{Dendritic cell activation assay}

Both the naturally derived ECM scaffolds and the fabricated RHCIII (singly- and doubly crosslinked) and (singly crosslinked) CMP-PEG hydrogels were tested for their ability to activate bone marrow DC by culturing freshly prepared "immature" (naïve) DC (iDC) in the presence of the gels and comparing their phenotype with DC cultured in the presence of LPS, a known inducer of "mature" DC (mDC). Natural collagen matrices, synthetic collagen hydrogels, and individual hydrogel constituents were tested using 96-well flat-bottom tissue culture plates (Thermo Fisher Scientific Inc., Waltham, 
MA). Gels and reagents were placed in the wells and cells added, at a concentration of $2 \times 10^{5}$ cells/well (in triplicate), and incubated at $37{ }^{\circ} \mathrm{C}, 5 \% \mathrm{CO}_{2}$. Prior to use, biomaterials were washed twice with sterile PBS to remove chloroform, trephined into $5 \mathrm{~mm}$ diameter disks to fit exactly in 96-well plates and sterilised (as described in 2.2.). Immature DC cultured in the absence of gels or reagents provided a negative control while DC cultured with LPS ( $1 \mu \mathrm{g} / \mathrm{mL}$; Sigma) provided the mDC positive control. Cells were cultured for 24 hours (P. Klaska \& V. Forrester, 2015; Vitova et al., 2013), or as indicated in Results, and both non-adherent cells (i.e. cells detached from the matrices and floating in the supernatant medium) and loosely adherent cells (i.e. cells obtained by gentle aspiration of fresh medium to the wells) (Inaba et al., 1992; Martin-Granados et al., 2015) were harvested and analysed by flow cytometry. Both engineered hydrogels and natural matrices were also examined for cell invasion by confocal microscopy. The phenotypic profiles of adherent or non-adherent DC were assessed using flow cytometry (see 2.5. below). The data in this report, unless otherwise stated (see 3.1. in Results), are centred on the loosely adherent cell population, since it contains the highest percentage of DC (Inaba et al., 1992; Martin-Granados et al., 2015).

\subsection{Flow cytometry}

Dendritic cells cultured with different naturally derived matrices and fabricated gels were assessed for their activation status by flow cytometry of cell surface markers and compared to control cultures of DC in the absence of gels. Control DC cultured in the absence of gels and without LPS were considered immature iDC and with LPS $(1.0 \mu \mathrm{g} / \mathrm{mL}, 1 \mathrm{~h})$ were considered mature (activated) mDC. Non-adherent and loosely adherent DC (Satpathy et al., 2012) were separately harvested and stained with fluorescently-labelled anti-mouse CD83 (Michel-19), CD86 (GL1), MHCII (AF6-120.1), CD11b (M1/70) or CD11c (HL3), all from BD Biosciences. Next, adherent, non-adherent DC, iDC or mDC were stained with fluorescently-labelled anti-mouse CD86 (GL1; Biolegend), MHCII (AF6-120.1; BD Biosciences), CD11b (M1/70; BD Biosciences), CD11c (HL3; BD Biosciences) and Zbtb46 (U4-1374; BD Biosciences) antibodies. Apoptosis was assessed by surface staining for Annexin V (strictly located intracellularly in non-apoptotic cells), and necrosis by using the phosphatidyl serine dead cell marker 7-aminoactinomycin $\mathrm{D}$ (7AAD, unable to access intact cells) in Annexin $\mathrm{V}$ binding buffer and 
confirmed using the FLICA-activated poly-caspases assay (all from BD Biosciences). Assays were performed as per the manufacturer's instructions. As positive controls (Pos apo), cells incubated at 70 ${ }^{\circ} \mathrm{C}$ for 30 min were used to induce apoptotic cell death and establish apoptosis gating strategies. All assays were performed as per manufacturers' protocols. To assess induction of tolerogenicity in gelcultured DC, the expression of collagen-binding leukocyte associated immunoglobulin-like receptor-1 (LAIR-1/CD305) (Nefla, Holzinger, Berenbaum, \& Jacques, 2016; L. Sprague et al., 2011) a characteristic marker of tolerogenic DC, was measured on the various DC populations (eBioscience, San Diego, CA). Samples were stained for 30 mins at $4{ }^{\circ} \mathrm{C}$ in the dark in FACS buffer [PBS with $1 \%$ (v/v) FCS, 2 mM ethylene diamine tetraacetic acid (EDTA) (Sigma-Aldrich, St. Louis, MO)], washed, and analysed using BD LSRII or BD Fortessa flow cytometers (BD Biosciences). Appropriate isotype controls or fluorescence minus one (FMO) controls were included to confirm absence of non-specific staining or fluorescence spillover, respectively. To assess the effect of the different culture conditions on cell cycle progression (i.e. cell proliferation), DNA-content was measured using DAPI nucleotide staining. For intracellular staining of the transcription factor Zbtb46, cells were fixed for 10 min using $1 \%(v / v)$ methanol-free formalin in PBS (both Sigma). For intra-cellular/intra-nuclear staining, cell membrane permeabilisation was established over 20 min using permeabilisation buffer $(0.1 \%$ Triton X-100 in PBS; both Sigma). Data analysis was completed using FlowJo V10 software (Tree Star, Ashland, OR).

\subsection{Confocal microscopy}

Following 24 hours of DC culture (as described in 2.4.), natural matrices or hydrogels were fixed in freshly prepared $4 \%(\mathrm{v} / \mathrm{v})$ methanol-free formalin (Thermo Scientific) in PBS $\left(15 \mathrm{~min}, 4^{\circ} \mathrm{C}\right)$ in flat-bottom 96-well plates, washed three times in PBS (2 min, room temperature (RT)) and incubated in absolute methanol (Sigma; 20 min, RT). These were then permeabilised with $0.2 \%$ (v/v) Triton X100 overnight at $4{ }^{\circ} \mathrm{C}$, washed and blocked (30 min, RT) with $10 \%$ (v/v) normal mouse serum diluted in PBS-BGEN [3 \% (w/v) bovine serum albumin (Fisher Scientific), $0.25 \%(\mathrm{w} / \mathrm{v})$ gelatin (Sigma), 5 mM EDTA and $0.025 \%$ octylphenoxypolyethoxyethanol (IGEPAL CA-630; Sigma), in PBS]. The samples were then stained with antibodies against fluorescently-labelled mouse MHCII, CD11b, CD11c 
or LAIR-1 (all from BD Biosciences) at effective concentrations of $\sim 5 \mu \mathrm{g} / \mathrm{mL}$ or concentrationmatched isotype controls, in PBS-BGEN overnight at $4{ }^{\circ} \mathrm{C}$ and washed. Hydrogels were then stained with rhodamine-phalloidin (F-actin; Sigma) to assess cytoskeletal shape (45 min, RT), washed and counterstained (20 min, RT) with 4',6-diamidino-2-phenylindol (DAPI; Thermo Fisher) for nuclear staining. After washing, hydrogels were mounted in anti-fade Vectashield (Vector Laboratories Inc., Burlingame, CA) mounted onto glass slides (Polysine slides, Thermo Scientific,) with coverslips (Thermo Fisher) and imaged using an LSM700 confocal microscope (Carl Zeiss, Oberkochen, Germany). Microscope settings were optimized uniquely for different gel compositions to compensate for gel intrinsic autofluorescence, and with differential interface contrast as necessary and image analysed using Zen Black software (Carl Zeiss, Oberkochen, Germany).

\subsection{Transwell ${ }^{\circledR}$ assay to assess DC invasiveness of collagen gels}

To assess the invasive potential of DC through natural matrices and manufactured hydrogels, a modified migration assay was performed using a $5 \mu \mathrm{m}$ pore Transwell® chamber (Corning HTS Transwell ${ }^{\circledR}$ 96-well plate, $5 \mu \mathrm{m}$ polycarbonate membrane). Gels were placed into the upper well of the chambers and DC added at a concentration of $2 \times 10^{5}$ cells/well. Cell migration into the body of the gel was measured by the leading front technique in which the distance migrated by the two leading cells into the gel was measured, using confocal imaging with an inbuilt micrometer after a fixed time of 3 hours at $37^{\circ} \mathrm{C}$. The number of cells in this plane was then quantified. Specifications on the respective thickness of those natural and manufactured biomaterials used in the Transwell ${ }^{\circledR}$ assay are to be found in 2.2 and 2.3 , respectively.

\subsection{Transwell ${ }^{\circledR}$ assay to assess chemoattractant potential of collagen gels}

To determine whether natural ECM or collagen hydrogels released components which might induce DC migration in a 'non-contact' manner, gels were placed in the lower chambers of each Transwell@, separated from DC plated in upper culture inserts $\left(3\right.$ hours, $\left.37^{\circ} \mathrm{C}\right)$ with media alone. The number of DC migrating into the lower chambers was quantified by flow cytometry as percentages of the total cells initially added to the upper compartment. Specifications on the respective thickness of 
those natural and manufactured biomaterials used in the Transwell ${ }^{\circledR}$ assay are to be found in $2.2,2.3$, and Figure 5, respectively.

\subsection{Statistical Analysis}

Statistical analyses were performed using a one-way analysis of variance with Tukey post-hoc test (based on homogeneous variances) or Student's $t$-test; $\mathrm{p} \leq 0.05$ considered significant, with appropriate comparisons using Graph Pad Prism V.5 (Graph Pad Software, La Jolla, CA) or using IBM SPSS 24 (IBM Corp. Released 2016. IBM SPSS Statistics for Windows; Version 24.0.; Armonk, NY: IBM Corp.).

\section{RESULTS}

\subsection{Preparation and phenotyping of immature DC from mouse bone marrow}

Conventional bone marrow DC (conventional DC, cDC) are classically identified by the integrins CD1 1c and CD11b, both of which are expressed at varying degrees also by other myeloid cells (Shortman \& Caux, 1997). More recently, the transcription factor Zbtb46 has been shown to be specific for conventional/classical DC, which in the bone marrow are considered progenitor/iDC (Meredith et al., 2012). In this study, DC were prepared from bone marrow as described (see 2.1. in Methods) and the percentage of Zbtb46 expression on the $\mathrm{CD} 11 \mathrm{~b}^{+} \mathrm{CD} 11 \mathrm{c}^{+} \mathrm{DC}$ was found to be $>98 \%$. Culture on different gel matrices such as Matrigel ${ }^{\mathrm{TM}}$ or the singly crosslinked RHCIII gel CMC-NHS did not significantly alter this expression (Supplementary Figure S1).

Culture of DC in vitro leads to some degree of maturation/activation in itself, which is reflected in the cells' behaviour (Inaba et al., 1992). Activation of DC with LPS (mDC) induced a significant increase in CD86 expression (Figure 1).

Dendritic cells cultured on both collagen gels and natural matrices behaved similarly to DC grown on cell culture plastic in that they formed three fractions: non-adherent cells, loosely adherent clusters, and firmly adherent spread cells. In this study, we have used the loosely adherent DC for the 
majority of experiments, unless otherwise noted (see 2.4. and 2.5. in Methods and Supplementary Figures S1 and S3) as this population of cells contains a higher proportion of DC (Lu et al., 1995). Loosely adherent cells (clusters (Inaba et al., 1992)) appear round with minimal or no dendritic processes. This morphology is similarly retained among DC across all states of activation. A proportion of DC remained firmly attached to the gel surface after $24 \mathrm{~h}$ incubation, and some appeared to invade the gel.

\subsection{Natural matrices and hydrogels variably activate immature DC}

We undertook a comprehensive study of DC behaviour in response to culture on various matrices. The biomaterials used in this study are described in Table 1. Our initial investigation was to assess DC activation using flow cytometry. Different gels activated DC to different extents, as compared to untreated iDC and LPS treated $\mathrm{mDC}$. Culturing DC on the natural matrices, Matrigel ${ }^{\mathrm{TM}}$ and de-cellularised cornea, induced no evidence of DC activation, and instead generated a tolerising environment for the cells with significantly reduced MHC Class II and CD86 expression, compared to the untreated control iDC (Figure 1). Singly crosslinked RHCIII gels mildly increased MHC Class II expression (significantly for CMC-NHS and non-significantly for EDC-NHS). In contrast to MHC Class II expression, all crosslinked gels induced upregulation of CD86 in DC (Figure 1B). Unlike RHCIII gels, CMP-PEG gels singly crosslinked with EDC-NHS did not clearly activate DC, in that MHC Class II expression was significantly reduced, and CD86 only mildly increased (Figure 1A and B). This showed that the crosslinking process was not necessarily a key factor in DC activation.

CD83 expression in DC followed a different pattern. As expected, LPS activation of DC mildly lowered CD83 expression although this was not significant (Figure 1C). Dendritic cells cultured on natural matrices had markedly reduced levels of CD83. The four fabricated hydrogels, however, yielded highly variable results. The CMC-NHS singly crosslinked hydrogel showed significantly reduced CD83 expression in DC while other gels induced significant upregulation of CD83, although to varying degrees (Figure 1C). Strong correlations were found between the percentage of cells expressing the above activation/maturation markers in the respective culture conditions (Supplementary Figure S2 A- 
C) and the level of their expression as measured by gMFI (Supplementary Figure S2 D-F). Interestingly, while there were similarly strong correlations between MHC class II expression on Zbtb $46^{+}$DC cultured on $18 \%$ RHCIII (CMC-NHS) gels and Matrigel ${ }^{\mathrm{TM}}$, CMC-NHS correlated positively while Matrigel ${ }^{\mathrm{TM}}$ correlated negatively with CD86 expression (Supplementary Figure S1 B-E). This finding supports the hypothesis that Matrigel ${ }^{\mathrm{TM}}$ generated a particularly non-activating (tolerising) environment for DC.

For collagen gels that tended to activate DC, neither the amount of collagen present $(10 \% v s$. $18 \%$ ), nor the presence or absence of the crosslinked MPC network appeared to affect the DC activation potential (data not shown). Therefore, further experiments were performed using $18 \%$ RHCIII hydrogels. In addition, to exclude the possibility that specific gel components induced DC activation, we tested native soluble collagen I and III, as well as those components used for generating crosslinked collagen gels, namely PEG and CMP-PEG uncrosslinked. (Table 1). Collagens I and III, and CMPPEG uncrosslinked did not induce DC activation, while DC exposure to PEG markedly suppressed expression of all three activation markers (data not shown).

Figure 1 here (in b/w in print).

As indicated above, a small number of firmly adherent DC appeared to infiltrate the gels and it was of interest to see whether this reflected their activation status. As shown in Figure 1D, DC infiltrating singly crosslinked RHCIII EDC-NHS hydrogels displayed strong surface MHCII expression while within also singly crosslinked CMP-PEG hydrogels (inset), MHCII expression was detected only intracellularly or dimly on cell surfaces. These data indicated that the comparably greater likelihood of RHCIII gels to activate DC was not related to their crosslinks. The same applied to cells infiltrating Matrigel $^{\mathrm{TM}}$ or corneal stroma which both failed to significantly induce DC.

\subsection{Natural matrices and RHCIII hydrogels induce high levels of (apoptotic) cell death in DC}

Apoptotic cells, including apoptotic DC, when engulfed by antigen presenting cells, promote immune tolerance (Kushwah \& Hu, 2010). Thus, we investigated whether the collagen matrices used 
in this study increased apoptosis in DC. Apoptosis was measured following DC culture on different biomaterials and compared to that of iDC cultured in their absence. LPS-activated $\mathrm{mDC}$ were used as a positive control (see 2.4. in Methods).

Lipopolysaccharide treatment neither lowered DC viability, nor changed levels of late apoptosis (Figure 2; Supplementary Figure S3A). In contrast, DC exposed to natural matrices (Matrigel ${ }^{\mathrm{TM}}$ and cornea) were significantly less viable and exhibited increased late apoptosis (cornea) (Figure 2A, B, and D). Early apoptosis did not significantly increase in either of the biomaterials/test conditions (Figure 2C). Among the fabricated hydrogels, higher percentages of DC cultured on low-activating singly crosslinked CMP-PEG hydrogels were late apoptotic (Figure 2D), while significantly higher numbers of DC were detected in CMC-NHS singly crosslinked hydrogel cultures (Figure 2B) as compared to the iDC condition. Using a complementary apoptosis assay (FLICA) the latter results were supported in that elevated levels of activated poly caspases (indicative of apoptosis) were measured for DC cultured on Matrigel $^{\mathrm{TM}}$ and CMC-NHS (Supplementary Figure S3 A) relative to iDC. Additionally, apoptosis was significantly correlated to an increased number of cells in the sub-G1 cell cycle phase exclusively

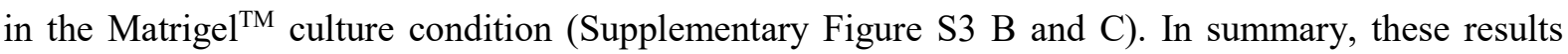
support the concept that possible tolerogenic properties of natural matrices and crosslinked RHCIII gels are reflected in their ability to induce apoptosis.

\subsection{Individual components of RHCIII hydrogels are pro-apoptotic}

Apoptosis levels were quantified for individual hydrogel components and data presented as fold change of percentage $\mathrm{CD} 11 \mathrm{~b}^{+} \mathrm{CD} 11 \mathrm{c}^{+} \mathrm{DC}$ relative to iDC. None of those substrates tested exerted a pro-apoptotic effect on DC with the exception of PEG (Figure 3). Interestingly, this compound on its own was toxic towards DC, while it had no pronounced effect when incorporated into a stable hydrogel matrix (CMP-PEG crosslinked) (Figure 2). PEG effects in DC included a decrease in live cells (Figure 3A) and corresponding increase in dead cells (Figure 3B) as well as relatively increased late apoptosis levels (Figure 3D), while it had no clear effect on early apoptosis (Figure 3C). Across all biomaterials tested (natural matrices, crosslinked gels and their components), strong and significant correlations were 
found between fold change in numbers of live DC presence and fold change DC maturation (CD86: R 0.5773, p 0.0493; and MHCII: R 0.7659, p 0.0037), further emphasizing the association between increased DC apoptosis acting as a trigger for DC tolerisation.

Figure 2 here (in b/w in print).

Figure 3 here (in b/w in print).

\subsection{LAIR-1 mediated recognition of natural matrices or RHCIII hydrogels}

Soluble collagen and collagen matrices are known to be immuno-inhibitory and some of their biological effect is due to the leukocyte-associated Ig receptor LAIR-1 (CD305). LAIR-1 is an immunoinhibitory, collagen-binding receptor constitutively expressed by various leukocyte types, including DC (Meyaard, 2008). We therefore investigated whether LAIR-1 expression was altered in iDC cultured on crosslinked collagen matrices. Dendritic cells exposed to both natural and manufactured collagen matrices showed an increase in expression of LAIR-1 to varying degrees (Figure 4A). For some matrices including Matrigel ${ }^{\mathrm{TM}}$, corneal stroma, singly- and doubly crosslinked RHCIII hydrogels, as well as singly crosslinked CMP-PEG, co-upregulation of LAIR-1 with Annexin V was found, indicating a link with apoptosis (Figure 4B). This was confirmed by a significant inverse correlation between LAIR-1 expression and the number of live DC (Figure 4C). Interestingly, cells which infiltrated the fabricated collagen matrices frequently expressed LAIR-1 (Figure 4D).

Figure 4 here (in b/w in print).

\subsection{Dendritic cells readily migrate through natural matrices and crosslinked hydrogels}

In their role as immune sentinels, DC traffic through extracellular matrices in their journey from the bone marrow to secondary lymphoid tissues (Steinman, 2012). To determine whether DC could also invade and migrate through engineered gels we assessed their migration in a modified Transwell ${ }^{\circledR}$ system (see 2.7. in Methods). Dendritic cells $\left(2 \times 10^{5}\right)$ were incubated with the gels in the upper 
Transwell ${ }^{\circledR}$ chamber (Figure 5A) for 3 hours. A small proportion of DC settled on each gel surface, while the majority of cells settled on the Transwell ${ }^{\circledR}$ membrane beneath the gels by passing over the gel surface. Accordingly, the percentage of cells migrating into the lower well was not affected by the presence of the gel in the upper well except visually in the case of Matrigel ${ }^{\mathrm{TM}}$ (Figure 5B), but this result is non-significant. Since Matrige ${ }^{\mathrm{TM}}$ was polymerised in situ (see 2.2. in Methods), forming a firm, cell impermeable adhesion to the chamber wall, the percentage of cells in the lower well in this case was predictably lower (Figure 5B).

The Transwell ${ }^{\circledR}$ system was therefore used to estimate the ability of cells to invade natural and manufactured crosslinked gels using the leading-front method (Figure 5C). Cells that settled onto the various gel surfaces and adhered firmly, generally invaded the gel to varying degrees, depending on the nature of the gel. Leading front measurements indicated that DC migrated essentially through the full thickness of de-cellularised corneal stroma, and through more than $75 \%$ of the thickness of singly crosslinked CMC-NHS, doubly crosslinked EDC-NHS, and singly crosslinked CMP-PEG hydrogels (Figure 5C). However, migration into Matrigel ${ }^{\mathrm{TM}}$ and singly crosslinked EDC-NHS alone was reduced to fifty percent of gel thickness indicating some degree of restriction of gel invasion (Figure 5C).

Gels were also assessed for their potential ability to induce DC migration (chemo-attractant properties) by placing them in the lower Transwell ${ }^{\circledR}$ chambers and determining contact-free DC migration from the lower into the upper chamber. None of the fabricated gels altered the migratory activity of DC over iDC controls. However, the natural matrix Matrigel ${ }^{\mathrm{TM}}$ in the lower well had a significant inhibitory effect on chemotactic DC migration (Figure 5D).

Figure 5 here (in b/w in print).

\section{DISCUSSION}

Activation of immune cells, particularly innate immune cells, by biomaterials used as surgical implants, is a major consideration when determining their suitability. This is particularly relevant in 
generating material for use as corneal grafts since not only has the material to induce minimal immune cell reaction, but also to remain transparent. Recently, activated DC, which are conventionally regarded as inducers of de novo $\mathrm{T}$ - and $\mathrm{B}$ cell adaptive immune responses against foreign antigens, have been flagged as having a role in wound healing through induction of B- and $\mathrm{T}$ cells. Most $\mathrm{T}$ cell subsets, including $\mathrm{CD}^{+}$(Th1 and Th2), $\mathrm{CD} 8^{+}$and $\mathrm{T}$ regulatory cells, have been implicated but a common denominator for fibrogenesis appears to be the production/liberation of activated TGF $\beta$ (Araya \& Nishimura, 2010; Brodeur et al., 2015; Farini et al., 2007; Kuttkat et al., 2017; L. Liu et al., 2012), which is also known to alternatively activate and thereby tolerise DC (Adnan et al., 2016; NaranjoGómez et al., 2011).

In some circumstances, the beneficial effects of DC-T cell interaction in promoting fibrogenesis has been demonstrated, as in the induction of interstitial fibrosis and left ventricular wall healing after myocardial infarction (Lichtman, 2013). In particular, the beneficial effect of CD28 $8^{+} \mathrm{T}$ cells activated via $\mathrm{CD} 80 / 86^{+} \mathrm{DC}$ in healing were highlighted, although the precise role of $\mathrm{T}$ effector cells versus Foxp $3^{+} \mathrm{T}$ regulatory cells remained to be clarified (Lichtman, 2013). While wound healing in the wall of the heart is clearly a desirable outcome, wound healing in the cornea may have deleterious functional effects if it causes opacification, and more so when this is accompanied by inflammation. This particularly affects wound healing in association with surgical implants and prostheses as applied to the cornea where the major complication is the formation of RCM (Hicks \& Hamilton, 2005; Obata \& Tsuru, 2007; Yum et al., 2013). These are, in effect, opaque fibrotic capsules (Küchle \& Green, 1996) which surround the corneal implant (Bakhtiari et al., 2012; Hicks \& Hamilton, 2005) and obstruct the transmission of light. The role of macrophages and other inflammatory cells in RCM formation is well known, and lymphocytes have been identified in RCM tissues surrounding corneal prostheses (Chalam, Chokshi, Agarwal, \& Edward, 2007) but whether these cells are bystander infiltrating cells or are a result of specific DC-T cell activation remains to be clarified.

Dendritic cells act as the sentinels of the immune system and survey the host tissues for “danger" signals (DAMPs, PAMPs) which include both foreign and damaged host antigens (J. Liu \& Cao, 2015), as for instance in myocardial infarction (Lichtman, 2013). In homeostasis, DC maintain 
naïve $\mathrm{T}$ cells in an inactivated state and are considered tolerogenic, but when activated by danger signals, DC convert to an immunogenic state by expressing cell surface activation markers such as CD80/86 and MHC Class II (Schultz et al., 2015). In the present study, we have compared natural collagen matrices and their soluble components with engineered recombinant collagen hydrogels, as potential corneal substitutes, for their DC activation potential. We show that natural matrices (i.e. corneal stroma, and Matrigel ${ }^{\mathrm{TM}}$ ) and soluble short-chain collagen peptides (CMP) do not activate DC (i.e. they remain tolerogenic). Somewhat in contrast, manufactured RHCIII hydrogels have variable effects on DC in that the singly crosslinked EDC-NHS gel induces high, and CMC-NHS mild levels of DC activation. Addition of a second crosslinked MPC network did not further increase DC activation, and in fact in part attenuated it. This is in keeping with reports that MPC has inflammation suppressing properties (Kakinoki et al., 2014; Yumoto et al., 2015). In addition, singly crosslinked CMP-PEG had minimal effect on DC activation (Figure 1). These data were further supported by strong and mostly significant correlations observed between intracellular Zbtb46 expression in DC and their activation (Supplementary Figure S1) when cultured on Matrigel $^{\mathrm{TM}}$ and singly crosslinked CMC-NHS, respectively. Interestingly, a negative correlation was found between CD86 and Zbtb46 following culture of DC on Matrigel $^{\mathrm{TM}}$ (Supplementary Figure S1 E) emphasizing a possible tolerising effect of Matrigel $^{\mathrm{TM}}$ on DC (Figure 1B). However, Matrigel ${ }^{\mathrm{TM}}$ contains many components in addition to collagen Type IV, such as other matrix proteins (CorningInc., 2018) as well as the TGF $\beta$ cytokine superfamily, some members of which are known to be tolerogenic for DC (reviewed in ref. (Seeger, Musso, \& Sozzani, 2015)). Further partial evidence for a tolerogenic role for collagen matrices was shown in the expression of CD83 by DC on exposure to the recombinant hydrogels. CD83 like CD80/86 binds CD28 on $\mathrm{T}$ cells but its expression level correlates with tolerogenicity (Kryczanowsky, Raker, Graulich, Domogalla, \& Steinbrink, 2016) and in its soluble form, as when shed from the DC surface, acts as a negative regulator of T cell activation (Horvatinovich et al., 2017). Dendritic cells, on exposure to both singly and doubly crosslinked EDC-NHS/-MPC, upregulated their expression of CD83 while on exposure to singly crosslinked CMC-NHS there was a reduced level of CD83 (Figure 1C). However, despite the lower MHC Class II and CD86 expression by DC on exposure to the natural matrices Matrigel $^{\mathrm{TM}}$ and corneal stroma, these matrices did not have an inverse CD83-inducing effect (Figure 
1A-C). This may reflect the more complex nature of these matrices since they are both extraction products, with not all bioactive components identified.

In general, therefore, natural collagen and other structural matrix proteins do not induce immune responses and are probably tolerogenic (Bayrak, Prüger, Stock, \& Seifert, 2013). Similarly, the fabricated matrices studied here are probably tolerogenic, but variably so, depending on the respective gel chemistry. Soluble collagen bound to tissue culture plastic is known to be non-activating for DC (Bayrak et al., 2013) and this is mediated via the collagen receptor LAIR-1 (Leslee Sprague et al., 2014). In the present study, both the natural matrices and the engineered collagen gels induced upregulation of LAIR-1, although to different degrees (Figure 4A). Exposure of DC to collagen matrices also induced variable degrees of apoptosis and cell death (Figure 3), a process which is also strongly linked to tolerogenicity (Frodermann et al., 2015; J. Liu \& Cao, 2015; Morelli \& Larregina, 2016). Importantly, there was a remarkable inverse correlation between LAIR-1 expression and numbers of live cell with respect to specific natural and manufactured matrices. Clearly, interaction between DC and collagen induces apoptosis via signalling mechanisms which involve LAIR-1. Other receptors on DC are known to bind collagen such as osteoclast-associated receptor (OSCAR) and glycoprotein VI (GPVI) but these are activating receptors and unlikely to be involved in induction of tolerance and promotion of wound healing (Zhou et al., 2016).

\section{CONCLUSIONS}

As indicated in this report hydrogel-specific DC maturation leading to $\mathrm{T}$ cell activation promotes fibrosis probably via induction of TGF $\beta 1$. With regard to the use of fabricated collagen implants as artificial corneas it is desirable to limit the degree of fibrosis and particularly inflammation. In the case of lamellar intrastromal collagen implants the least DC-activating biomimetic collagen matrix would be the implant of choice. However, lamellar implants have application for use only in cases of corneal opacification where the endothelium is intact and functional. For many cases of corneal blindness, particularly in rural communities of developing nations, full thickness (penetrating) collagen 
implants would be necessary, and in such cases a level of wound healing sufficient to ensure good wound closure is crucial. Therefore, biomaterials with no to minimal DC-activating potential would be optimal to allow for corneal regeneration in the absence of inflammation.

\section{ACKNOWLEDGEMENTS}

We are grateful to the Iain Fraser Flow Cytometry Centre, the Microscopy and Histology Facility, and the Medical Research Facility at the University of Aberdeen. This work was supported by the Royal College of Surgeons of Edinburgh, UK; and Saving Sight in Grampian/Development Trust of the University of Aberdeen, UK.

\section{CONFLICT OF INTEREST STATEMENT}

The authors CM, SPS, MMI, JVF and LK have no competing interest to declare. MG is a co-founder and minority shareholder in UAB Ferentis which holds a UK patent for the 38 aa CMP molecule and CMP-PEG hydrogel described in this study (inventor: Jaywant Phopase) and patents pending. 


\section{REFERENCES}

Adnan, E., Matsumoto, T., Ishizaki, J., Onishi, S., Suemori, K., Yasukawa, M., \& Hasegawa, H. (2016). Human tolerogenic dendritic cells generated with protein kinase $\mathrm{C}$ inhibitor are optimal for functional regulatory $\mathrm{T}$ cell induction - A comparative study. Clinical Immunology, 173(Supplement C), 96-108. doi:https://doi.org/10.1016/i.clim.2016.09.007

Ahn, J. I., Kuffova, L., Merrett, K., Mitra, D., Forrester, J. V., Li, F., \& Griffith, M. (2013). Crosslinked collagen hydrogels as corneal implants: effects of sterically bulky vs. non-bulky carbodiimides as crosslinkers. Acta Biomaterialia, 9(8), 7796-7805. doi:doi: 10.1016/j.actbio.2013.04.014.

Anderson, J. M., Rodriguez, A., \& Chang, D. T. (2008). Foreign body reaction to biomaterials. Seminars in Immunology, 20(2), 86-100. doi:10.1016/j.smim.2007.11.004

Araya, J., \& Nishimura, S. L. (2010). Fibrogenic Reactions in Lung Disease. Annual Review of Pathology, 5(1), 77-98. doi:10.1146/annurev.pathol.4.110807.092217

Babensee, J. E. (2008). Interaction of dendritic cells with biomaterials. Seminars in Immunology, 20(2), 101-108. doi:10.1016/j.smim.2007.10.013

Badylak, S. F., \& Gilbert, T. W. (2008). Immune response to biologic scaffold materials. Seminars in Immunology, 20(2), 109-116. doi:10.1016/j.smim.2007.11.003

Bakhtiari, P., Chan, C., Welder, J. D., de la Cruz, J., Holland, E. J., \& Djalilian, A. R. (2012). Surgical and Visual Outcomes of the Type I Boston Keratoprosthesis for the Management of Aniridic Fibrosis Syndrome in Congenital Aniridia. American Journal of Ophthalmology, 153(5), 967971.e962. doi:http://dx.doi.org/10.1016/j.ajo.2011.10.027

Banchereau, J., \& Steinman, R. M. (1998). Dendritic cells and the control of immunity. Nature, 392(6673), 245-252. doi:10.1038/32588

Bayrak, A., Prüger, P., Stock, U. A., \& Seifert, M. (2013). Absence of Immune Responses with Xenogeneic Collagen and Elastin. Tissue Engineering. Part A., 19(13-14), 1592-1600. doi:10.1089/ten.tea.2012.0394

Brodeur, T. Y., Robidoux, T. E., Weinstein, J. S., Craft, J., Swain, S. L., \& Marshak-Rothstein, A. (2015). IL-21 Promotes Pulmonary Fibrosis through the Induction of Profibrotic CD8+ T Cells. Journal of Immunology, 195(11), 5251-5260. doi:10.4049/jimmunol.1500777

Buznyk, O., Pasyechnikova, N., Islam, M. M., lakymenko, S., Fagerholm, P., \& Griffith, M. (2015). Bioengineered Corneas Grafted as Alternatives to Human Donor Corneas in Three High-Risk Patients. Clinical and Translational Science, 8(5), 558-562. doi:10.1111/cts.12293

Chalam, K. V., Chokshi, A., Agarwal, S., \& Edward, D. P. (2007). Complications of AlphaCor Keratoprosthesis: A Clinicopathologic Report. Cornea, 26(10), 1258-1260. doi:10.1097/ICO.0b013e31813e0bd8

CorningInc. (2018). Corning Matrigel Matrix, Frequently Asked Questions. In (Vol. 2018): https://www.corning.com/media/worldwide/cls/documents/CLS-DL-CC-026\%20DL.pdf.

Dang, Z., Kuffová, L., Liu, L., \& Forrester, J. (2014). Soluble antigen traffics rapidly and selectively from the corneal surface to the eye draining lymph node and activates T cells when codelivered with CpG oligonucleotides. Journal of Leukocyte Biology, 95(3), 431-440. doi:10.1189/jlb.0612294.

Fagerholm, P., Lagali, N. S., Merrett, K., Jackson, W. B., Munger, R., Liu, Y., . . Griffith, M. (2010). A Biosynthetic Alternative to Human Donor Tissue for Inducing Corneal Regeneration: 24-Month Follow-Up of a Phase 1 Clinical Study. Science Translational Medicine, 2(46), 46ra61.

Fagerholm, P., Lagali, N. S., Ong, J. A., Merrett, K., Jackson, W. B., Polarek, J. W., . . Griffith, M. (2014). Stable corneal regeneration four years after implantation of a cell-free recombinant human collagen scaffold. Biomaterials, 35(8), 2420-2427 doi:doi: 10.1016/j.biomaterials.2013.11.079.

Farini, A., Meregalli, M., Belicchi, M., Battistelli, M., Parolini, D., D'Antona, G., . . Torrente, Y. (2007). $\mathrm{T}$ and $\mathrm{B}$ lymphocyte depletion has a marked effect on the fibrosis of dystrophic skeletal muscles in the scid/mdx mouse. The Journal of Pathology, 213(2), 229-238. doi:10.1002/path.2213 
Frodermann, V., van Puijvelde, G. H. M., Wierts, L., Lagraauw, H. M., Foks, A. C., van Santbrink, P. J., . . de Jager, S. C. A. (2015). Oxidized Low-Density Lipoprotein-Induced Apoptotic Dendritic Cells as a Novel Therapy for Atherosclerosis. Seminars in Immunology, 194(5), 2208-2218. doi:10.4049/jimmunol.1401843

Griffith, M., Polisetti, N., Kuffova, L., Gallar, J., Forrester, J. V., Vemuganti, G. K., \& Fuchsluger, T. A. (2012). Regenerative approaches as alternatives to donor allografting for restoration of corneal function. The Ocular Surface, 10(3), 170-183. doi:doi: 10.1016/j.jtos.2012.04.004.

Hamrah, P., Liu, Y., Zhang, Q., \& Dana, M. R. (2003). The corneal stroma is endowed with a significant number of resident dendritic cells. Investigative Ophthalmology and Visual Science, 44(2), 581-589. doi:10.1167/iovs.02-0838

Hayes, S., Lewis, P., Islam, M. M., Doutch, J., Sorensen, T., White, T., . . Meek, K. M. (2015). The structural and optical properties of type III human collagen biosynthetic corneal substitutes. Acta Biomaterialia, 25, 121-130. doi:http://dx.doi.org/10.1016/i.actbio.2015.07.009

Hicks, C. R., \& Hamilton, S. (2005). Retroprosthetic Membranes in AlphaCor Patients: Risk Factors and Prevention. Cornea, 24(6), 692-698.

Horvatinovich, J. M., Grogan, E. W., Norris, M., Steinkasserer, A., Lemos, H., Mellor, A. L., . . . DeBenedette, M. A. (2017). Soluble CD83 Inhibits T Cell Activation by Binding to the TLR4/MD2 Complex on CD14+ Monocytes. Journal of Immunology, 198(6), 2286-2301. doi:10.4049/jimmunol.1600802

Inaba, K., Inaba, M., Romani, N., Aya, H., Deguchi, M., Ikehara, S., . . . Steinman, R. M. (1992). Generation of large numbers of dendritic cells from mouse bone marrow cultures supplemented with granulocyte/macrophage colony-stimulating factor. Journal of Experimental Medicine, 176(6), 1693-1702. doi:10.1084/jem.176.6.1693

Islam, M. M., Buznyk, O., Reddy, J. C., Pasyechnikova, N., Alarcon, E. I., Hayes, S., . . Griffith, M. (2018). Biomaterials-enabled cornea regeneration in patients at high risk for rejection of donor tissue transplantation. npj Regenerative Medicine, 3(1), 2. doi:10.1038/s41536-017-0038-8

Islam, M. M., Ravichandran, R., Olsen, D., Ljunggren, M. K., Fagerholm, P., Lee, C. J., . . Phopase, J. (2016). Self-assembled collagen-like-peptide implants as alternatives to human donor corneal transplantation. RSC Advances, 6(61), 55745-55749. doi:10.1039/C6RA08895C

Janeway, C. A. J., \& Medzhitov, R. (2002). Innate immune recognition. Annual Review of Immunology, 20, 197-216. doi:10.1146/annurev.immunol.20.083001.084359

Jangamreddy, J. R., Haagdorens, M. K. C., Mirazul Islam, M., Lewis, P., Samanta, A., Fagerholm, P., ... Griffith, M. (2018). Short peptide analogs as alternatives to collagen in pro-regenerative corneal implants. Acta Biomaterialia, 69, 120-130. doi:10.1016/j.actbio.2018.01.011

Jones, K. S. (2008). Effects of biomaterial-induced inflammation on fibrosis and rejection. Seminars in Immunology, 20(2), 130-136. doi:10.1016/j.smim.2007.11.005.

Kakinoki, S., Sakai, Y., Takemura, T., Hanagata, N., Fujisato, T., Ishihara, K., \& Yamaoka, T. (2014). Gene chip/PCR-array analysis of tissue response to 2-methacryloyloxyethyl phosphorylcholine (MPC) polymer surfaces in a mouse subcutaneous transplantation system. Journal of Biomaterials Science, Polymer Edition, 25(14-15), 1658-1672. doi:10.1080/09205063.2014.939917

Kryczanowsky, F., Raker, V., Graulich, E., Domogalla, M. P., \& Steinbrink, K. (2016). IL-10-Modulated Human Dendritic Cells for Clinical Use: Identification of a Stable and Migratory Subset with Improved Tolerogenic Activity. Journal of Immunology, 197(9), 3607-3617. doi:10.4049/jimmunol.1501769

Küchle, M., \& Green, W. R. (1996). Epithelial ingrowth: a study of 207 histopathologically proven cases. German Journal of Ophthalmology, 5(4), 211-223.

Kuffová, L., Netuková, M., Duncan, L., Porter, A., Stockinger, B., \& Forrester, J. V. (2008). Cross presentation of antigen on MHC class II via the draining lymph node after corneal transplantation in mice. Journal of Immunology, 180(3), 1353-1361. doi:10.4049/ jimmunol.180.3.1353 
Kushwah, R., \& Hu, J. (2010). Dendritic Cell Apoptosis: Regulation of Tolerance versus Immunity. Journal of Immunology, 185(2), 795-802. doi:10.4049/jimmunol.1000325

Kuttkat, N., Mohs, A., Ohl, K., Hooiveld, G., Longerich, T., Tenbrock, K., ... Trautwein, C. (2017). Hepatic overexpression of cAMP-responsive element modulator $\alpha$ induces a regulatory T-cell response in a murine model of chronic liver disease. Gut. doi:10.1136/gutjnl-2015-311119

Lichtman, A. H. (2013). The heart of the matter: Protection of the myocardium from T cells. Journal of Autoimmunity, 45, 90-96. doi:http://dx.doi.org/10.1016/i.jaut.2013.05.004

Liu, J., \& Cao, X. (2015). Regulatory dendritic cells in autoimmunity: A comprehensive review. Journal of Autoimmunity, 63, 1-12. doi:http://dx.doi.org/10.1016/i.jaut.2015.07.011

Liu, L., Kou, P., Zeng, Q., Pei, G., Li, Y., Liang, H., . . Chen, S. (2012). CD4+ T Lymphocytes, Especially Th2 Cells, Contribute to the Progress of Renal Fibrosis. American Journal of Nephrology, 36(4), 386-396.

Liu, W., Merrett, K., Griffith, M., Fagerholm, P., Dravida, S., Heyne, B., . . Li, F. (2008). Recombinant human collagen for tissue engineered corneal substitutes. Biomaterials, 29(9), 1147-1158. doi:10.1016/j.biomaterials.2007.11.011

Lu, L., Hsieh, M., Oriss, T. B., Morel, P. A., Starzl, T. E., Rao, A. S., \& Thomson, A. W. (1995). Generation of DC from mouse spleen cell cultures in response to GM-CSF: immunophenotypic and functional analyses. Immunology, 84(1), 127-134.

Martin-Granados, C., Prescott, A. R., Le Sommer, S., Klaska, I. P., Yu, T., Muckersie, E., . . Forrester, J. V. (2015). A key role for PTP1B in dendritic cell maturation, migration, and T cell activation. Journal of Molecular Cell Biology, 7(6), 517-528. doi:10.1093/jmcb/mjv032.

McLaughlin, C. R., Acosta, M. C., Luna, C., Liu, W., Belmonte, C., Griffith, M., \& Gallar, J. (2010). Regeneration of functional nerves within full thickness collagen-phosphorylcholine corneal substitute implants in guinea pigs. Biomaterials, 31(10), 2770-2778. doi:doi: 10.1016/j.biomaterials.2009.12.031.

Meredith, M. M., Liu, K., Darrasse-Jeze, G., Kamphorst, A. O., Schreiber, H. A., Guermonprez, P., . . . Nussenzweig, M. C. (2012). Expression of the zinc finger transcription factor ZDC (Zbtb46, Btbd4) defines the classical dendritic cell lineage. Journal of Experimental Medicine, 209(6), 1153-1165. doi:10.1084/jem.20112675

Meyaard, L. (2008). The inhibitory collagen receptor LAIR-1 (CD305) Journal of Leukocyte Biology, 83(4), 799-803. doi:doi: 10.1189/jlb.0907609

Morelli, A. E., \& Larregina, A. T. (2016). Concise Review: Mechanisms Behind Apoptotic Cell-Based Therapies Against Transplant Rejection and Graft versus Host Disease. Stem Cells, 34(5), 11421150. doi:10.1002/stem.2326

Naranjo-Gómez, M., Raïch-Regué, D., Oñate, C., Grau-López, L., Ramo-Tello, C., Pujol-Borrell, R., . . . Borràs, F. E. (2011). Comparative study of clinical grade human tolerogenic dendritic cells. Journal of Translational Medicine, 9(1), 89. doi:10.1186/1479-5876-9-89

Nefla, M., Holzinger, D., Berenbaum, F., \& Jacques, C. (2016). The danger from within: alarmins in arthritis. Nature Reviews: Rheumatology, 12(11), 669-683. doi:10.1038/nrrheum.2016.162

O'Leary, L. E. R., Fallas, J. A., Bakota, E. L., Kang, M. K., \& Hartgerink, J. D. (2011). Multi-hierarchical self-assembly of a collagen mimetic peptide from triple helix to nanofibre and hydrogel. $\begin{array}{lll}\text { Nature } \quad \text { Chemistry, 3(10), 821-828. } & \text {. }\end{array}$ doi:http://www.nature.com/nchem/journal/v3/n10/abs/nchem.1123.html\#supplementaryinformation

Obata, H., \& Tsuru, T. (2007). Corneal Wound Healing from the Perspective of Keratoplasty Specimens With Special Reference to the Function of the Bowman Layer and Descemet Membrane. Cornea, 26, S82-S89. doi:10.1097/ICO.0b013e31812f6f1b

P. Klaska, I., \& V. Forrester, J. (2015). Mouse Models of Autoimmune Uveitis. Current Pharmaceutical Design, 21(18), 2453-2467.

Park, J., \& Babensee, J. E. (2012). Differential functional effects of biomaterials on dendritic cell maturation. Acta Biomaterialia, 8(10), 3606-3617. doi:10.1016/j.actbio.2012.06.006 
Rajendran, V., Netuková, M., Griffith, M., Forrester, J. V., \& Kuffová, L. (2017). Mesenchymal stem cell therapy for retro-corneal membrane - A clinical challenge in full-thickness transplantation of biosynthetic corneal equivalents. Acta Biomaterialia, 64(Supplement C), 346-356. doi:https://doi.org/10.1016/i.actbio.2017.10.011

Reddy, S. T., Swartz, M. A., \& Hubbell, J. A. (2006). Targeting dendritic cells with biomaterials: developing the next generation of vaccines. Trends in Immunology, 12, 573-579. doi:10.1016/j.it.2006.10.005

Rubert Pérez, C. M., Stephanopoulos, N., Sur, S., Lee, S. S., Newcomb, C., \& Stupp, S. I. (2015). The Powerful Functions of Peptide-Based Bioactive Matrices for Regenerative Medicine. Annals of Biomedical Engineering, 43(3), 501-514. doi:10.1007/s10439-014-1166-6

Satpathy, A. T., KC, W., Albring, J. C., Edelson, B. T., Kretzer, N. M., Bhattacharya, D., ... Murphy, K. M. (2012). Zbtb46 expression distinguishes classical dendritic cells and their committed progenitors from other immune lineages. Journal of Experimental Medicine, 209(6), 11351152. doi:10.1084/jem.20120030

Schultz, H. S., Nitze, L. M., Zeuthen, L. H., Keller, P., Gruhler, A., Pass, J., . . Panina, S. (2015). Collagen Induces Maturation of Human Monocyte-Derived Dendritic Cells by Signaling through Osteoclast-Associated Receptor. Journal of Immunology, 194(7), 3169-3179. doi:10.4049/jimmunol.1402800

Seeger, P., Musso, T., \& Sozzani, S. (2015). The TGF- $\beta$ superfamily in dendritic cell biology. Cytokine and Growth Factor Reviews, 26(6), 647-657. doi:http://dx.doi.org/10.1016/j.cytogfr.2015.06.002

Sefton, M. V., Babensee, J. E., \& Woodhouse, K. A. (2008). Innate and adaptive immune responses in tissue engineering. Seminars in Immunology, 20(2), 83-85 doi:doi: 10.1016/j.smim.2007.12.008.

Shankar, S. P., Griffith, M., Forrester, J. V., \& Kuffová, L. (2015). Dendritic cells and the extracellular matrix: A challenge for maintaining tolerance/homeostasis. World Journal of Immunology, 5(3), 113-130. doi:10.5411/WJI.v5.i3.113

Shankar, S. P., Petrie, T. A., García, A. J., \& Babensee, J. E. (2010). Dendritic cell responses to selfassembled monolayers of defined chemistries. Journal of Biomedical Materials Research. Part A., 92(4), 1487-1499. doi:10.1002/jbm.a.32487

Shortman, K., \& Caux, C. (1997). Dendritic cell development: multiple pathways to nature's adjuvants. Stem Cells, 15, 409-419 doi:DOI: 10.1002/stem.150409

Sprague, L., Muccioli, M., Pate, M., Meles, E., McGinty, J., Nandigam, H., . . Benencia, F. (2011). The interplay between surfaces and soluble factors define the immunologic and angiogenic properties of myeloid dendritic cells. BMC Immunology, 12, 35:31-22. doi:doi: 10.1186/14712172-12-35.

Sprague, L., Muccioli, M., Pate, M., Singh, M., Xiong, C., Ostermann, A., . . Benencia, F. (2014). Dendritic cells: In vitro culture in two- and three-dimensional collagen systems and expression of collagen receptors in tumors and atherosclerotic microenvironments. Experimental Cell Research, 323(1), 7-27. doi:http://dx.doi.org/10.1016/i.yexcr.2014.01.031

Steinman, R. M. (2012). Decisions about dendritic cells: past, present, and future. Annual Review of Immunology, 30, 1-22 doi:DOI: 10.1146/annurev-immunol-100311-102839

Tang, L., \& Eaton, J. W. (1995). Inflammatory responses to biomaterials. American Journal of Clinical Pathology, 103(4), 466-471. doi:http://dx.doi.org/10.1093/ajcp/103.4.466

van Kooten, C., Lombardi, G., Gelderman, K. A., Sagoo, P., Buckland, M., Lechler, R., \& Cuturi, M. C. (2011). Dendritic cells as a tool to induce transplantation tolerance: obstacles and opportunities. Transplantation, 91(1), 2-7. doi:0.1097/TP.0b013e31820263b3

Vitova, A., Kuffová, L., Klaska, I. P., Holan, V., Cornall, R. J., \& Forrester, J. V. (2013). The high-risk corneal regraft model: a justification for tissue matching in humans. 26(4), 453-461. doi:doi:10.1111/tri.12055 
Yum, H. R., Kim, M. S., \& Kim, E. C. (2013). Retrocorneal Membrane After Descemet Membrane Endothelial Keratoplasty. Cornea, 32(9), 1288-1290. doi:10.1097/ICO.0b013e318296e0f7

Yumoto, H., Hirota, K., Hirao, K., Miyazaki, T., Yamamoto, N., Miyamoto, K., . . Miyake, Y. (2015). Antiinflammatory and protective effects of 2-methacryloyloxyethyl phosphorylcholine polymer on oral epithelial cells. Journal of Biomedical Materials Research. Part A., 103(2), 555-563. doi:doi:10.1002/jbm.a.35201

Zhang, M. C., Liu, X., Jin, Y., Jiang, D. L., Wei, X. S., \& Xie, H. T. (2015). Lamellar keratoplasty treatment of fungal corneal ulcers with acellular porcine corneal stroma. American Journal of Transplantation, 15(4), 1068-1075. doi:10.1111/ajt.13096. Epub 2015 Mar 11.

Zhou, L., Hinerman, J. M., Blaszczyk, M., Miller, J. L. C., Conrady, D. G., Barrow, A. D., . . Herr, A. B. (2016). Structural basis for collagen recognition by the immune receptor OSCAR. Blood, 127(5), 529-537. doi:10.1182/blood-2015-08-667055 


\section{TABLES}

Table 1: Classification and composition of natural and engineered (fabricated/manufactured) biomaterials used in this study.

\section{FIGURES}

Figure 1: Comparison of activation of DC by natural matrices ("natural"), or engineered hydrogels ("engineered") to untreated (immature DC, iDC) or LPS-activated (mature DC, mDC) controls ("ctrl") at 24 hours, all cultured on tissue culture plastic. DC maturation marker expression is presented as fold change in gMFI for MHCII (A), CD86 (B), and CD83 (C) for CD11b ${ }^{+}$CD11 $c^{+}$cells. Mean $\pm \mathrm{SD} ; \mathrm{N}=$ 3-8, unpaired $t$ test; *different from iDC ( $\mathrm{p} \leq 0.05$, one-way ANOVA with Tukey post-hoc test), $\wedge$ different from cornea; levels of significance: ${ }^{*} \mathrm{p} \leq 0.05,{ }^{*} \mathrm{p} \leq 0.01,{ }^{* * *} \mathrm{p} \leq 0.001,{ }^{* * * *} \mathrm{p}<0.0001$. Representative images $(\mathrm{N}=3)$ depicting MHCII expression on DC (with DAPI nucleophilic counterstaining) which infiltrated natural matrices or engineered hydrogels; 40X magnification (inset 20X), scale bar $20 \mu \mathrm{m}(\mathrm{D})$.

Figure 2: Increased levels of apoptosis in $\mathrm{CD} 11 \mathrm{~b}^{+} \mathrm{CD} 11 \mathrm{c}^{+} \mathrm{DC}$ cultured for 24 hours on natural matrices ("natural") or engineered hydrogels ("engineered") versus untreated and LPS-activated controls ("ctrl"), all cultured on tissue culture plastic. Percentages of cells are expressed as fold change over the negative control (iDC). Live: unstained (A), dead: 7-AAD positive (B), early apoptotic: Annexin V positive (C), and late apoptotic: double positive for 7-AAD and Annexin V (D) CD11 b $\mathrm{b}^{+} \mathrm{CD} 11 \mathrm{c}^{+} \mathrm{DC}$, following culture over natural matrices or engineered hydrogels. Mean $\pm \mathrm{SD} ; \mathrm{N}=3-8$, one-way ANOVA with Tukey post-hoc test, $* * *$ different from iDC $(\mathrm{p} \leq 0.0001)$. 
Figure 3: Effect of individual components of biomaterials ("components") on DC apoptosis compared to untreated (iDC) or LPS-activated DC (mDC) controls ("ctrl"). Percentages of cells are expressed as fold change over the negative control (iDC). Live: unstained (A), dead: 7-AAD positive (B), early apoptotic: Annexin V positive (C), and late apoptotic: double positive for 7-AAD and Annexin V (D) $\mathrm{CD} 11 \mathrm{~b}^{+} \mathrm{CD} 11 \mathrm{c}^{+} \mathrm{DC}$ are depicted, following culture with individual biomaterial components. Mean \pm $\mathrm{SD} ; \mathrm{N}=3-8$, one-way ANOVA with Tukey post-hoc test, *different from iDC and $\mathrm{mDC}(\mathrm{p} \leq 0.05)$.

Figure 4: Comparison of LAIR-1 expression by CD11 $\mathrm{b}^{+} \mathrm{CD} 11 \mathrm{c}^{+} \mathrm{DC}$ cultured for 24 hours on natural matrices ("natural") or engineered hydrogels ("engineered") versus untreated and LPS-activated controls ("ctrl"), all cultured on tissue culture plastic. Increased expression of LAIR-1 was observed in DC cultured on Matrigel ${ }^{\mathrm{TM}}$, singly crosslinked CMC-NHS or doubly crosslinked MPC RHCIII hydrogels, but not after culture on singly crosslinked CMP-PEG hydrogels over the negative control (iDC). Fold change in LAIR-1 based on gMFI (A), or fold change based on percentages of Annexin $\mathrm{V}^{+}$ LAIR- $1^{+}$DC (B); mean $\pm \mathrm{SD} ; \mathrm{N}=3$, unpaired t test, ${ }^{*}$ different from iDC, ${ }^{*} \mathrm{p} \leq 0.05,{ }^{* *} \mathrm{p} \leq 0.01,{ }^{* * *} \mathrm{p}$ $\leq 0.001, * * * * \mathrm{p}<0.0001$. A strongly negative correlation (C) was found between fold change gMFI LAIR-1 expression and fold change percentage live DC (both over iDC) for different biomaterials (mean $\pm \mathrm{SD} ; \mathrm{N}=3$, R: Pearson's coefficient $-1 \leq 0 \leq 1$; two-tailed $\mathrm{p} \leq 0.05$ is significant). Representative images $(n=3)$ showing LAIR-1 expression (with DAPI nucleophilic staining) on DC which infiltrated into natural materials or engineered hydrogels during $24 \mathrm{~h}$ culture (D).

Figure 5: Schematic of migration assay Transwell ${ }^{\circledR}$ chamber system with natural matrix ("natural”) or engineered hydrogel ("engineered") placed on membrane in upper chamber (A). Percental migratory cell events detected in lower chambers are presented (mean $\pm \mathrm{SD} ; \mathrm{N}=3$, unpaired $t$-test) (B). Depth of leading edge across biomaterials are presented as percentages of total material thickness (mean $\pm \mathrm{SD}$; $\mathrm{N}=3$, unpaired t test, *different from iDC, $\left.{ }^{*} \mathrm{p} \leq 0.05\right)(\mathrm{C})$. Chemotactic ("non-contact") migratory cell 
events from lower to upper chamber presented as fold change over iDC controls ("ctrl”) (mean $\pm \mathrm{SD}$; $\mathrm{N}=3$; unpaired t test *different from iDC, $* * * * \mathrm{p}<0.0001)(\mathrm{D})$.

Graphical abstract: Bone marrow immature dendritic cells (iDC) were cultured on a series of engineered differentially cross-linked hydrogels containing recombinant human collagen (RHCIII) or collagen mimetic peptide (CMP). Upon culture of DC over the different hydrogels cell surface expression of activation/maturation markers (CD86, MHC II) was assessed and compared to controls (natural matrices).

Left: Natural matrices (Matrigel ${ }^{\mathrm{TM}}$ and de-cellularized mouse corneal stroma) induced no DC activation and maintained their "tolerogenic" status (tolDC). The same was true for the cross-linked collagen mimetic peptide CMP-PEG hydrogel. The RHCIII gel CMC-NHS crosslinked with N-cyclohexyl-N(2-morpholinoethyl) carbodiimide metho-p-toulenesulfonate with N-hydroxy succinimide (NHS) was only low activating.

Right: In contrast, the RHCIII gel cross-linked with N-(3-dimethylaminopropyl)-N'-ethylcarbodiimide containing the co-initiator N-hydroxy succinimide (EDC-NHS) or (CMC-NHS gels) induced high levels of $\mathrm{DC}$ activation, generating mature $\mathrm{DC}(\mathrm{mDC})$. 
Table 1

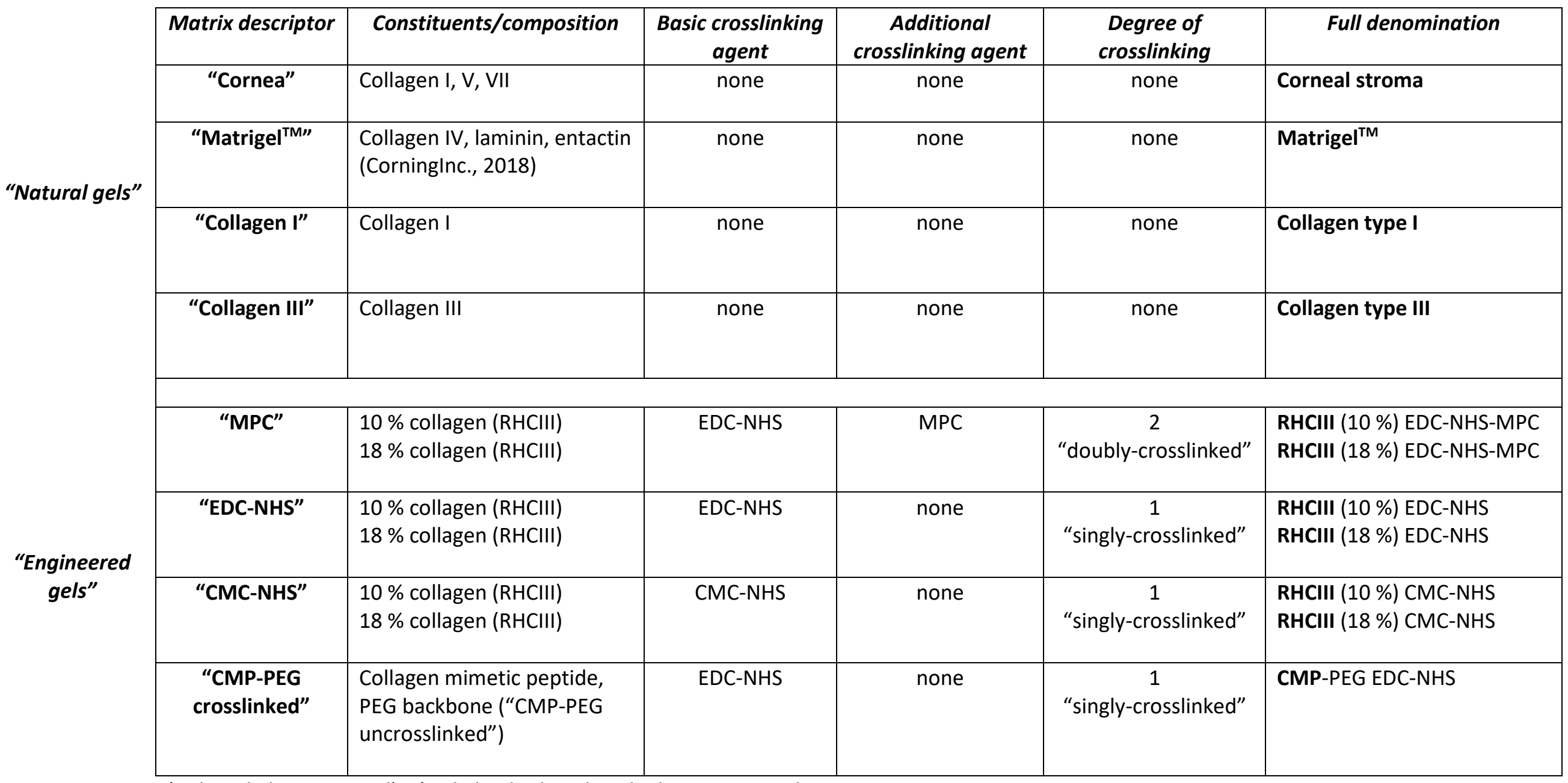

EDC-NHS: N-(3-dimethylaminopropyl)-N`-ethylcarbodiimide; $N$-hydroxysuccinimide

MPC: 2-methacryloyloxyethyl phosphorylcholine

CMC-NHS: N-cyclohexyl-N'-(2-morpholinoethyl)carbodiimidemetho-p-toluenesulphonate

CMP: Collagen Mimetic Peptide [(Pro-Lys-Gly)4(Pro-Hyp-Gly)4(Asp-Hyp-Gly)4]; 
Table 1: Classification and composition of natural and engineered (fabricated/manufactured) biomaterials used in this study 